were estimated by the investigators, as low, medium and high according to the repetitive and force work in the upper extremity.

Results All patients were male. Median age was 49 years (range: 33 to 52 ) in AS and 51 (25 to 60 ) in EN. Nineteen $(6,2 \%)$ cases were diagnosed in AS (10 ST, $8 \mathrm{LE}$ and $1 \mathrm{ME}$ ), and only 9 $(2,2 \%)$ in EN (7 ST and $2 \mathrm{LE})(\mathrm{p}=0.009)$. The cases were classified according to the factory and to the level of UEPR as follow:

AS/EN Low (2/5) Medium (6/3) High (11/1).

Annual and cummulative (95-99) risk proportion (\%) were (see Table 1):

An association between the type of factory (EN or AS) and the level of UEPR was observed, being the latter higher in AS ( $p$ $=0.04$ ). Relative risk of suffering LE, ME and ST was 2.8 (IC95: 1,3-6,1) in AS. Dominant side was affected in most cases $22(79 \%),(\mathrm{p}=0.002)$.

\begin{tabular}{lllllll}
\multicolumn{6}{l}{ Abstract FRI0251 Table 1} \\
\hline & 1995 & 1996 & 1997 & 1998 & 1999 & $95-99$ \\
\hline AS & 0.96 & 2.33 & 1.03 & 1.43 & 0.74 & 6.33 \\
EN & 0.66 & 0.24 & 0.50 & 0.21 & 0.39 & 1.96 \\
\hline
\end{tabular}

Conclusion Our data suggest that tasks with high UEPR have a relevant role in soft tissue lessions of the upper extremity and they are more frequent in the dominant side.

\section{FRI0252 EOSINOPHILIC MYOSITIS ASSOCIATED WITH BEHCET'S DISEASE}

B Coleiro, C Mallia. Department of Medicine, St Luke's Hospital, Pieta, Malta

10.1136/annrheumdis-2001.573

Behcet's disease, a systemic vasculitis of unknown aetiology, has a variety of clinical manifestations, the commoner ones including recurrent oro-genital ulceration, uveitis and rashes. Muscular involvement is an uncommon clinical feature and a review of the literature by Worthmann $\mathrm{F}$ et al. ${ }^{1}$ suggests that the myositis passes through two different stages of inflammation: a granulocytic-monocytic phase followed by a predominantly lymphocytic infiltration phase. We present the case of a 24 year old male who satisfies the International Study Group criteria for the diagnosis of Behcet's disease, ${ }^{2}$ and who developed features of a localised myositis which differs from that described in the literature in that, histologically, the inflammatory cell infiltrate included significant eosinophilia.

\section{REFERENCES}

1 Worthmann $F$, et al. Muscular involvement in Behcet's disease: Case report and review of the literature. Neurosci Disord. 1996:6(4):247-53

2 International Study Group for Behcet's Disease. Criteria for diagnosis of Behcet's disease. Lancet 1990:335:1078-80

\section{FRI0253 EOSINOPHILIC FASCIITIS: RETROSPECTIVE EVALUATION OF 7 CASES}

E Tunc, V Inal, G Keser, T Pirildar, T Türk, K Aksu, Y Kabasakal, F Oksel, E Doganavsargil. Rheumatology, Ege University Medical Faculty, Izmir, Turkey
Background Eosinophilic fasciitis (EF) is a rare disorder characterised by scleroderma-like enduration of the skin, predominantly on the extremities and peripheral eosinophilia. Absence of Raynaud's phenomenon and visceral involvement are typical features. Histologic findings include fibrosis of muscle fascia and eosinophilic infiltration. Different clinical entities are reported in association with EF. Hereby, we aimed to present clinical characteristics of our cases.

Objectives The medical data of 7 patients with EF (F/M:4/3; mean age $41.7 \pm 19$ ), who were followed up for $22.7 \pm 19.6$ months in Ege University Rheumatology department between January 1996 and December 2000. Mean disease duration was $11 \pm 9.2$ months on initial diagnosis. The diagnosis was made by en-block biopsy. Skin enduration was located on the lower and upper extremities in all cases. In one patient there was additional enduration on trunk. All cases had peripheral eosinophilia and hypergammaglobulinemia. Elevated muscle enzymes were present only in one case. High titer ANA positivity was present only in three female cases. 2 cases had carpal tunnel syndrome, one had interstitial eosinophilic pneumonia, one had pericarditis and Hashimato thyroiditis, one had vitiligo, one had type II DM which began simultaneously and one had psoriasis in association with EF. There were no history of any relevant medication and toxic material ingestion. No one had malignancy in the followup period.

Initial treatment consisted of methylprednisolone $(32 \mathrm{mg} /$ day $)$ and methotrexate $(10 \mathrm{mg} /$ week). Since in literature, high serum histamin levels and good response to $\mathrm{H} 2$ blockers were reported, ranitidine was also added to this treatment1. All the patients responded well; however one case was resistant to this treatment. D-penicillamine $(150 \mathrm{mg} /$ day $)$ and colchicine $(1 \mathrm{mg} / \mathrm{day})$ treatment were added for this patient. Skin endurations regressed in all cases. Two patient had complete and the other five had partial remission.

Methods

Results

Conclusion In conclusion, the diagnosis of EF should be always confirmed by en-block biopsy and presence of associated autoimmune pathologies should be kept in mind and searched. Malignancy should always be excluded. Response to appropriate treatment is generally satisfactory.

\section{REFERENCE}

1 Naschitz JE, Boss JH, Misselevich I, Yesfurun D, Rosner I. The fasciitis-panniculitis syndromes. Clinical and pathologic features. Medicine (Baltimore) 1996;75(1):616

\section{FRI0254 CHURG-STRAUSS SYNDROME (CSS) IN A SERIES OF 14 PATIENTS: A TWELVE YEARS EXPERIENCE}

J Mazzotti, G Riccio, E Venegoni, P Bottero. Uo Medicine, Section of Immunology, "G. Fornaroli" Hospital, Magenta (Milan), Italy

10.1136/annrheumdis-2001.575

Background Between 1988 and 200014 patients affected by CSS have been followed. Our series included 9 females and 5 males, the mean age at the diagnosis was 54 years (range 2178 ), the mean follow up period was 95 months (range 60-141). Four criteria were simultaneneously satisfied in all patients at the diagnosis, according to the vasculitis ACR classification. The most important clinical manifestations exept for asthma, eosinophilia and paranasal sinus abnormality costantly present, were arthralgias, cutaneous nodules, peripheral neuropathy. Renal and 